\title{
ESTIMATION OF CLIMATIC PARAMETERS FROM SOLAR INDICES USING GROUND BASED DATA FROM KENYA, EAST AFRICA
}

\author{
J. O. H. Ndeda, , ${ }^{2}$ A. B. Rabiu,,${ }^{3}$ L. H. M. Ngoo, , and ${ }^{4}$ G. O. Ouma, \\ ${ }^{1}$ Dept. of Physics, Jomo Kenyatta University of Agriculture \& Technology JKUAT. P.O. Box \\ 62000-00200, Nairobi, Kenya. \\ ${ }^{2}$ Center for Space Research and Applications, Federal University of Technology, Akure, Nigeria. \\ ${ }^{3}$ Dept. of Electrical Engineering, JKUAT. P.O. Box 62000-00200, Nairobi, Kenya. \\ ${ }^{4}$ Dept. of Meteorology, University of Nairobi. P.O. Box 30197-00100, Nairobi, Kenya.
}

\begin{abstract}
The daily meteorological data of relative humidity, maximum, minimum, and average temperatures obtained from five stations of the Kenya Meteorological Department over the period 1986 to 2005 were filtered and reduced to monthly means. Monthly data of solar indices: Sunspot number, F10.7 cm solar radio flux and Mg II core-to-wing ratio covering the same period were employed to model the meteorological variables using the linear multivariate model and applying least square fittings. Validity of the models was tested using Mean Bias Error (MBE) and Root Mean Square Error (RMSE) statistical indicators. The correlations between the observed and predicted values from the models were significant at above $95 \%$ level of confidence. The models show the effect of solar forcing on the climatic parameters at different locations in Kenya. Solar forcing of climate is evident in Kenya.
\end{abstract}

Keywords: modeling, climatic parameters, solar indices, statistical indicators.

\section{INTRODUCTION}

Climate change has for long remained an object of keen intensive research. The climate of our own Earth is rooted in the troposphere, a region in the altitude range $0-17 \mathrm{~km}$. Attempts have been made to establish a coupling effect among the various layers of the Earth's atmosphere. Such attempts include: Labitzke and Van Loon (1988); Rabiu et al. (2005). Impact of solar activity in Earth's terrestrial environment is propagated from the heliosphere via the interplanetary medium to the lower atmosphere which has troposphere at its lower end. Solar activity affects the dynamics of the troposphere and influence the weather of the Earth.
Rabiu and Omotosho (2003) reported negative relationship between the total column tropospheric ozone concentration in tropical Nigeria and solar activity. Rabiu et al., (2005) also established the linear dependence of surface air temperature on solar activity after obtaining negative correlation coefficients between the annual means of surface air temperature and sunspot number both at two stations. The negative correlation was explicable in terms of tropospheric heating mechanisms in response to solar activity. They asserted that the negative correlation observed at all time scales is quite in agreement with the results of Labitzke (1987), Labitzke and Van Loon (1988), Labitzk 


\section{Ndeda et al.}

and Chanin (1988), Chanin (1988), and Nikolashkin et al. (2001) who have shown that a negative correlation exists between solar activity and atmospheric temperature up to $50 \mathrm{~km}$. Rabiu et al. (2005) used polynomial relationship to model the surface temperatures from sunspot numbers. Ndeda et al. (2009) established similarities in periods of Meteorological variables over Kenya and Solar Activity periods. Scafetta and West (2008) linked the changes in the Earth's average surface temperature directly to two distinctly different aspects of the Sun's dynamics: the short-term statistical fluctuations in the Sun's irradiance and the longer-term solar cycles. They had earlier (Scafetta and West, 2003) showed that the stochastic properties of the average global temperature are linked to the statistics of Total Solar Irradiance TSA, and estimated that 'the Sun could account for as much as $69 \%$ of the increase in Earth's temperature, depending on the Total Solar Irradiance TSI reconstruction used' (Scafetta and West, 2007).

In this study, the climatic parameters: Relative Humidity and Temperature, from the Kenya Meteorological Department (KMD) for five observatories in different climatic zones were modeled with the solar irradiance using the solar parameters: Sunspot Numbers $\left(R_{s}\right)$, the $\mathrm{F} 10.7 \mathrm{~cm}$ solar radio flux (F10.7) and $\mathrm{Mg}$ II core-to-wing ratio $(\mathrm{Mg} \mathrm{II})$ to determine the solar forcing of the Kenyan climate. The solar indices used in this study are the Sunspot Numbers $\left(\mathrm{R}_{\mathrm{s}}\right)$, the $\mathrm{F} 10.7 \mathrm{~cm}$ solar radio flux (F10.7) and $\mathrm{Mg}$ II core-to-wing ratio (Mg II) which measure the activities of the sun in the photosphere, the corona and the chromospheres, respectively. Sunspots are the most easily observed features of the solar photosphere, while at the same time they are important manifestations of solar activity (Györi et al., 2004). Starting in 1996, space observations by the Michelson Doppler Imager (MDI) on Solar Heliophysical Observatory (SOHO) have also become available; (Győri et al.,2004). Sunspots are seen as the centers of activity on the solar surface (Akasofu and Chapman, 1972).

The solar $10.7 \mathrm{~cm}$ flux is the solar flux density measured at a wavelength of $10.7 \mathrm{~cm}$ in the UV region of the spectrum. The radio emission from the sun at a wavelength of 10.7 centimeters (the $10 \mathrm{~cm}$ flux) correlates well with the sunspot number $\left(\mathrm{R}_{\mathrm{s}}\right)$. NOAA Mg II Core-towing ratio is derived from the ratio of the $h$ to $k$ lines of the solar Mg II feature at $280 \mathrm{~nm}$ to the background or wings at approximately $278 \mathrm{~nm}$ and $282 \mathrm{~nm}$. The $h$ and $k$ lines are variable chromospheric emissions while the background emissions are more stable. The Mg II Core-towing ratio is a robust measure of solar chromospheric activity.

\section{RESEARCH METHODOLOGY}

Modeling the Meteorological and Solar Variables

Monthly data records of relative humidity (RH), maximum temperature (MAT) and minimum temperature (MIT) for the years 1986 2005 were obtained at five terrestrial stations representing the regional climatic zones under the management of the Kenya Meteorological Department (KMD). The experimental sites represent the different climatic variations of the country. Monthly average temperature (AVT) values for the same period were calculated from MIT and MAT values. Table 1 presents the geographical coordinates of the stations whose data were used in this study.

Table 1: Geographical coordinates of the meteorological stations

\begin{tabular}{llllc}
\hline Stations (Site) & Code & Latitude & Longitude $\left({ }^{\circ} \mathbf{E}\right)$ & Altitude $(\mathbf{m})$ \\
\hline Kericho & $\mathrm{KER}$ & $0.4\left({ }^{\circ} \mathrm{S}\right)$ & 35.3 & 1946.85 \\
Dagoretti (Nairobi) & $\mathrm{NBI}$ & $1.3\left({ }^{\circ} \mathrm{S}\right)$ & 36.8 & 1771.77 \\
Kisumu & $\mathrm{KSM}$ & $0.1\left({ }^{\circ} \mathrm{S}\right)$ & 34.8 & 131.83 \\
Mombasa & $\mathrm{MSA}$ & $4.0\left({ }^{\circ} \mathrm{S}\right)$ & 39.6 & 5.41 \\
Garissa & $\mathrm{GRS}$ & $0.5\left({ }^{\circ} \mathrm{N}\right)$ & 39.6 & 120.13 \\
\hline
\end{tabular}




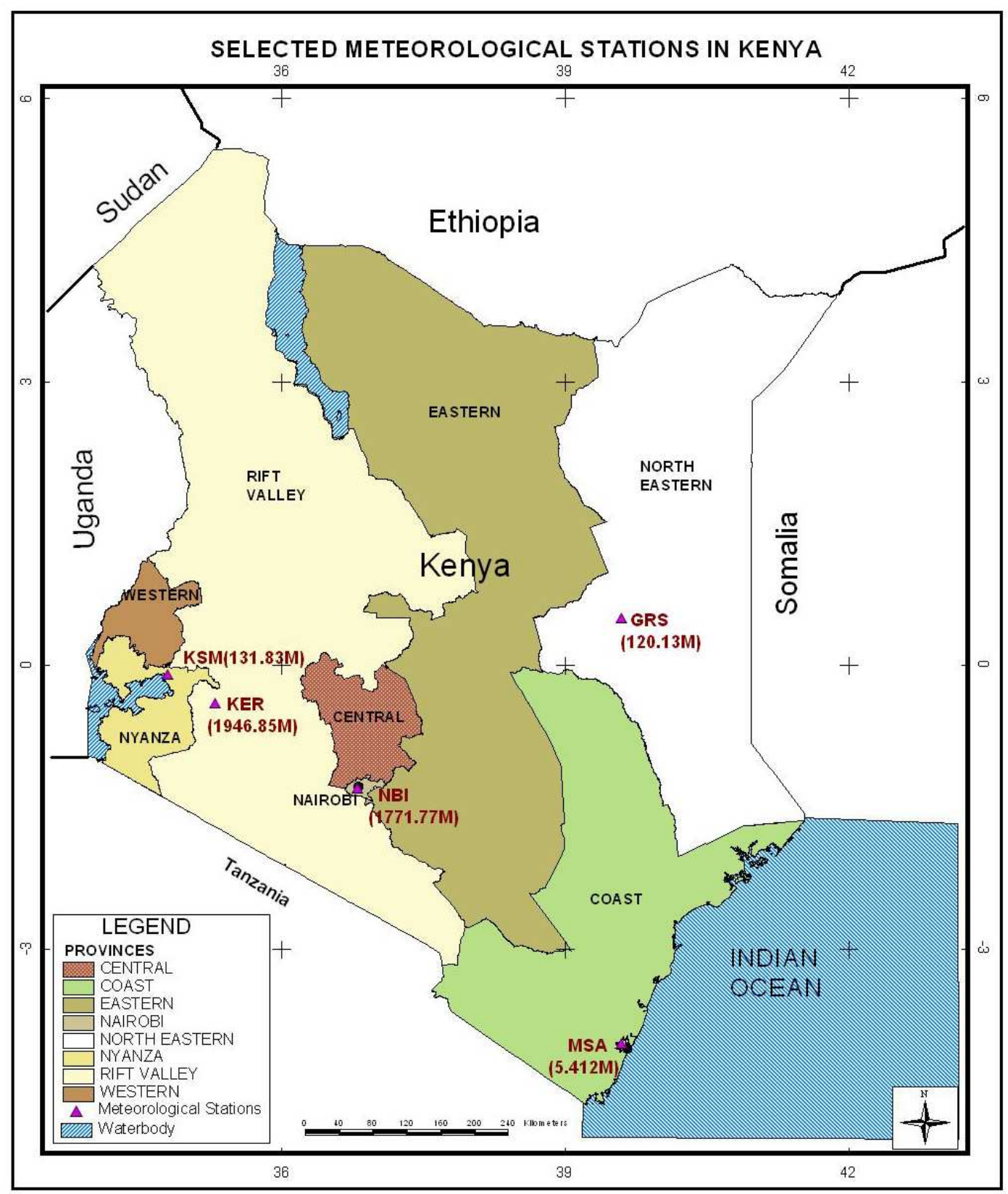

Fig.1. Map of Kenya showing locations of the stations (Courtesy Regional Centre for Mapping of Resources for Development: RCMRD, Nairobi) 


\section{Ndeda et al.}

The Kericho site represents the western highlands of the rift valley province. It is located near Kericho town, in the western high lands of the rift valley, about $87 \mathrm{~km}$ from Lake Victoria. These features give it a fairly cold weather and persistent rains throughout the year. It is a tea zone area. Access is by road.

The Nairobi site represents the central highland region that spans the central, Nairobi and parts of Eastern provinces. The site is located within the premises of the KMD headquarters, four kilometers from the Nairobi city centre. It is in the central highlands of Kenya that influences the weather patterns here. It is accessible by road network throughout the year. Being within the city of Nairobi, the area is not forested. But it is within the neighborhoods of the forested Karen and Ngong' estates. The soil type is loamy, and can support coffee and other seasonal food crops like maize and beans.

Kisumu site represents the influence of the smaller water body proximity of Lake Victoria, which is largely in Nyanza and parts of the Western provinces. The site is located within the shores of Lake Victoria, within the Kisumu city airport. It is a fairly hot region with a long rainy season from March to May, and short rainy season in September/October to December every year. It is accessible throughout the year by road network and by air. It is within the precinct of the Equator. The soil type is firm and rocky, and supports food crops such as sorghum, maize, beans and yams. Sugar-cane and Cotton are also grown in the neighborhood of the station.

Mombasa site represents proximity of the large Ocean environment that covers the whole of the coast province bordering the Indian Ocean. The site is located within the coastal city of Mombasa. This is the city bordering the Indian Ocean which gives it a unique humidity. The area is known for cashew nuts, cassava, palm trees and sisal.

The Garissa site represents the arid and semi arid features that span the whole of North Eastern province of the country. The semi arid features make the place have characteristic long periods of no rain. Sporadic rains are, however, experienced in this region. The region is also famous for raising livestock such as camels, goats and indigenous cattle.

Assuming the meteorological variable $\mathrm{y}$ is expressible in terms of the solar indices $\mathrm{R}_{\mathrm{s}}, \mathrm{F}_{10.7}$ and $\mathrm{Mg}$ II such that:

$y=y\left(R_{S}, F_{10.7}, M g I I\right)$ an empirical linear multivariate model of the form below is proposed:

$y=A+B R_{s}+C F_{10.7}+D M g I I$

Where ' $y$ ' is any of the meteorological variables; $R_{s}$ is the sunspot number; $F_{10.7}$ is the $F 10.7 \mathrm{~cm}$ solar radio flux index and $\mathrm{Mg}$ II is the $\mathrm{Mg}$ II core-to-wing ratio index respective values. A, B, C and D are empirical coefficients that are determined by least square fittings. The values of these coefficients are presented in the multivariate models 4 to 23 .

\section{Performance of Models}

The validity of the model was tested using the statistical indicators employed by Falayi and Rabiu (2005) and El-Metwally (2005). The Mean Bias Error (MBE) and Root Mean Square Error (RMSE) were evaluated using the following equations for the meteorological variables at the five stations:

$M B E=\sum \frac{\left(y_{\text {pred }}-y_{\text {obs }}\right)}{N}$
$R M S E=\left[\sum\left(\frac{\left(y_{\text {pred }}-y_{\text {obs }}\right)^{2}}{N}\right)\right]^{1 / 2}$

$y_{\text {pred }}$ is the calculated value from the model, $y_{o b s}$ is the observed value and $N$ is the total number of observations. The test of RMSE provides information on the short-term performance of studied model as it allows a term by term comparison of the actual deviation between the calculated value and the measured value. Iqbal (1993) and Halouani et al. (1993) have recom- 
mended that a zero value of RMSE is ideal while a low MBE is desirable. The MBE and RMSE values obtained were well within the recommended values as to validate the models.

\section{RESULTS AND DISCUSSIONS}

The models represented in equations 4 to 23 show the solar forcing of RH, MAT, MIT and AVT respectively.

Relative Humidity (RH) and solar indices KER:RH=-33.7938-0.1391R $\quad+0.0628 \mathrm{~F} 10.7+$ $382.59 \mathrm{Mg}$ II

$\mathrm{NBI}: \mathrm{RH}=18.3722+0.1385 \mathrm{R}_{\mathrm{s}}-0.1714 \mathrm{~F} 10.7+$ 273.4407Mg II

KSM:RH=-50.4949+0.0894R $\mathrm{R}_{\mathrm{s}}-0.1383 \mathrm{~F} 10.7+$ $477.1217 \mathrm{Mg}$ II

MSA:RH $=58.5081+0.1140 \mathrm{R}_{\mathrm{s}}-0.1375 \mathrm{~F} 10.7+$ $117.3244 \mathrm{Mg}$ II

GRS:RH=167.7331-0.0454R +0.0888 F $10.7-$ $388.261 \mathrm{Mg}$ II

The models presented in equations 4 to 8 show the solar forcing of RH at all the stations. Models 5 to 7 for NBI, KSM and MSA indicate direct forcing of sunspot numbers and inverse forcing of F10.7. In KER and GRS meteorological stations; equations 4 and 8 respectively, show that $R_{s}$ has negative forcing of $\mathrm{RH}$ while F10.7 has positive forcing of RH. The uniqueness of KER is attributable to the orography of KER as has been stated. The lowland semi arid features of GRS favors the inverse forcing of RH observed.

Positive forcing of $\mathrm{Mg}$ II on $\mathrm{RH}$ is evident in all the stations except GRS. GRS actually shows negative forcing of sunspot number and $\mathrm{Mg}$ II on RH; But positive forcing of F10.7 on RH. This is attributable to the semi arid features characterizing that region. The high coefficients of $\mathrm{Mg}$ II in the models indicate that forcing due to the chromosphere and hence the solar ultraviolet radiation is more prominent on meteorological parameters in this study compared to photosphere and corona.

Maximum Temperature (MAT) and solar indices

KER:MAT $=88.8943+0.0417 R_{\mathrm{s}}-0.0061 \mathrm{~F} 10.7$ $-251.6985 \mathrm{Mg}$ II

NBI:MAT $=57.8234-0.0545 R_{s}+0.0733 \mathrm{~F} 10.7-$ $144.8584 \mathrm{Mg}$ II

KSM:MAT $=48.5030-0.0112 \mathrm{R}_{\mathrm{s}}+0.0198 \mathrm{~F} 10.7-$ $75.5191 \mathrm{Mg}$ II

MSA:MAT $=6.1165-0.0495 \mathrm{R}_{\mathrm{s}}+0.0391 \mathrm{~F} 10.7+$ $84.6753 \mathrm{Mg}$ II

GRS:MAT $=47.4955-0.0316 R_{\mathrm{s}}+0.0447 \mathrm{~F} 10.7-$ $60.0679 \mathrm{Mg}$ II

The models presented in equations 9 to 13 show the solar forcing of MAT at all the stations. All the models here indicate reasonable positive constant. Models in equations 10 to 13 indicate negative forcing of sunspot number on maximum temperature. The model in equation 9 for KER indicates positive forcing of $R_{s}$ on MAT. Uniqueness of KER is seen in this case as was observed in relative humidity.

All stations apart from KER indicate positive forcing of the coronal index F10.7 on maximum temperature. The uniqueness of KER in this case shows the consistency earlier observed.

The index of the chromosphere, $\mathrm{Mg}$ II has negative forcing on maximum temperature in all the stations except in the case of MSA as demonstrated in equations 9 to 13 . The unique case of MSA is attributed to the proximity of the Indian Ocean. The solar activities in the chromosphere, through Mg II, hence solar ultraviolet radiation has positive forcing of the maximum temperatures recorded in the coastal region. 


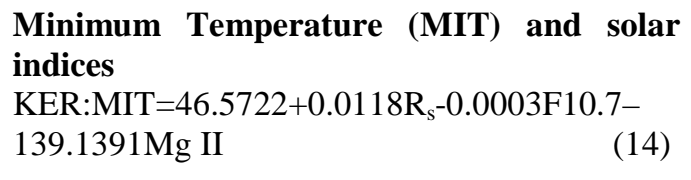

NBI:MIT $=11.7282-0.0232 R_{s}+0.0202 F 10.7+$ $2.2811 \mathrm{Mg}$ II

KSM: MIT $=6.9808-0.0100 R_{\mathrm{s}}+0.0031 \mathrm{~F} 10.7$ $+39.07461 \mathrm{Mg}$ II

MSA:MIT $=-53.8120-0.0057 \mathrm{R}_{\mathrm{s}}-0.0310 \mathrm{~F} 10.7+$ 297.5030Mg II

GRS:MIT $=60.9028-0.0094 R_{\mathrm{s}}+0.0305 \mathrm{~F} 10.7-$ $149.5705 \mathrm{Mg}$ II

The models presented in equations 14 to 18 show the solar forcing of MIT at all the stations. The models in equations 15 to 18 indicate that the index of the photosphere, the sunspot numbers, has negative forcing of minimum temperature. In KER (equation 14) it has positive forcing. The same reason as stated for $\mathrm{RH}$ and MAT over KER applies here.

NBI, KSM and GRS stations indicate positive forcing of F10.7 on MIT, while KER and MSA show inverse forcing. The coastal climate of MSA is the possible explanation to this deviation.

A high value of positive forcing of the index of the chromoshpere, $\mathrm{Mg}$ II is seen in equations 15 to 17 for NBI, KSM and MSA. The exact opposite is the case in KER and GRS. While the uniqueness of KER has been explained for the cases of RH and MAT, the GRS is attributable to the unique lowland semi arid climate there.

Average Temperature (AVT) and solar indices

KER:AVT $=67.7332+0.0267 \mathrm{R}_{\mathrm{s}}-0.0032 \mathrm{~F} 10.7-$ $195.4188 \mathrm{Mg}$ II

NBI:AVT $=-105.7111-0.0942 R_{\mathrm{s}}+0.0239 \mathrm{~F} 10.7+$ 472.5642Mg II
KSM:AVT $=27.7419-0.0106 R_{\mathrm{s}}+0.0115 \mathrm{~F} 10.7-$ 18.222Mg II

MSA:AVT $=-23.8478-0.0276 R_{\mathrm{s}}+0.0040 \mathrm{~F} 10.7$ $+191.0892 \mathrm{Mg}$ II

GRS:AVT=54.1991-0.0205R $+0.0376 \mathrm{~F} 10.7-$ $104.8192 \mathrm{Mg}$ II

The models presented in equations 19 to 23 show the solar forcing of AVT at all the stations. Inverse forcing of sunspot numbers on AVT is evident in all the meteorological stations except KER as seen in models of equations 20 to 23. KER shows positive forcing. The same reasons as earlier stated for other parameters can explain the unique case of KER.

Positive forcing of F10.7 on AVT is evident in all the meteorological stations except KER. KER shows inverse forcing. The same reasons as earlier stated for other parameters can explain the unique case of KER.

Inverse forcing of $\mathrm{Mg}$ II on AVT is evident in KER, KSM and GRS but positive forcing in NBI and MSA. The positive forcing in the two major cities can be explained in terms of modifications by the Urban Heat Island effect.

Correlations between the predicted and observed values of the climatic parameters

When the models were subjected to test by using the monthly solar indices data from January 2006 to October 2007 (20 months data), the correlation coefficients between the observed and predicted climatic parameters that were obtained per meteorological station are given in Table 2 (columns 2 to 6 ). In column 7, we have the correlations between the observed and predicted values when data from all the stations are pooled, not station wise. This is for longer data of 100 months for all the five stations, each having the 20 months of the climatic parameters data.

From Table 2 (columns 2 to 6 ), the positive correlations between the observed and pre- 
dicted RH are quite strong in KER $(r=0.67)$ and $\operatorname{KSM}(\mathrm{r}=0.52)$ at the 0.01 and 0.05 levels of significance respectively. MSA gives a fair correlation at $\mathrm{r}=0.5$. This is an indication that the RH model can best be used in the western highland rift valley of KER and close to the large water bodies in KSM and MSA.

Only the negative correlation between observed and predicted MAT in KER $(r=-0.68)$ is statistically significant at the 0.05 level (2-tailed). Some substantial positive correlation between observed and predicted MAT are in NBI and MSA. This shows that the MAT model is best applied in the low temperature area of the western highlands of rift valley, and the coastal and central highland areas to a limited extent.

From Table 2 (column 7), we see that when we have long time data, the predicted values for all parameters are statistically significant at the 0.01 level (2-tailed). The model works best for temperature (MAX, MIN, and AVT) with the correlation coefficient of about 0.9 . We used $95 \%$ of confidence level to validate the models; however, there are significant correlations between the solar indices and climatic variables in the stations.

\section{CONCLUSIONS}

All the models in equations 4 to 23 show solar indices forcing of the climatic parameters. The statistical indicators MBE and RMSE validate the models as recommended by Iqbal, (1993) and Halouani et al. (1993). The following con- clusions can be drawn from the models:

1. The photosphere through its index, the sunspot number has positive forcing of Relative humidity $(\mathrm{RH})$; while the corona, through its index $\mathrm{F} 10.7 \mathrm{~cm}$ solar radio flux has negative forcing of RH in Kenya, except for KER and GRS meteorological stations where the scenario is opposite. Solar Ultraviolet (UV) radiation through the proxy $\mathrm{Mg}$ II core to wing ratio which is the index of the chromosphere has positive forcing of RH in Kenya. The lowland semi arid region of north Eastern Kenya influences the opposite trend of forcing. The models give predicted values that correlate well with the observed values for KER, KSM and MSA when short time data are used; but they give predicted values that correlate better with observed values when longer duration data are used.

2. The photosphere through its index, the sunspot number has negative forcing of Temperature (MAT, MIT and AVT); while the corona, through its index F10.7 has positive forcing of Temperature in Kenya, except for KER meteorological station. Solar UV radiation through the proxy $\mathrm{Mg}$ II, which is the index of the chromosphere, has negative forcing of MAT in Kenya, except for MSA where there is negative forcing. $\mathrm{Mg}$ II, however, shows general negative forcing of MIT and AVT in majority of the stations considered in this study. Positive forcing is, however, prevalent in KER and GRS for MIT; and in NBI and MSA for

Table 2. Correlations between the model predicted and observed values of climatic parameters per station

\begin{tabular}{lllllll}
\hline $\begin{array}{l}\text { Climatic } \\
\text { Parameter }\end{array}$ & NBI & KER & KSM & MSA & GRS & $\begin{array}{l}\text { Corr. Coefficient (All sta- } \\
\text { tions' data used): 100 } \\
\text { months data. }\end{array}$ \\
\hline RH & -0.15 & $0.67 * *$ & $0.52^{* *}$ & 0.52 & 0.33 & $0.64 * *$ \\
MAT & 0.52 & $-0.68^{* *}$ & 0.29 & 0.58 & -0.08 & $0.89^{* *}$ \\
MIT & 0.21 & 0.21 & -0.3 & 0.14 & 0.26 & $0.96 * *$ \\
AVT & -0.35 & 0.34 & 0.34 & 0.02 & 0.26 & $0.90 * *$ \\
\hline
\end{tabular}

$* *$ Correlation significant at the 0.01 level (2-tailed). *Correlation Significant at the 0.05 level (2tailed) 


\section{Ndeda et al.}

AVT. The MAT model for KER gives predicted values that correlate well with observed values when short time data are used; but they give predicted values that correlate better with observed values $(r=0.89)$ when longer duration data are used. It is also clear that longer period predictions can be done for MIT and AVT $(r \geq 0.9)$ between predicted and observed values when longer time data are used in model testing).

\section{ACKNOWLEDGEMENT}

Special acknowledgement goes to the Director of the Kenya Meteorological Department, Nairobi for providing the meteorological data used in this research; and to the National Geophysical Data Centre (NGDC), Colorado for the solar indices data used for modeling and for testing the models. ABR is grateful to African Network of Scientific Institutions ANSTI for awarding visiting fellowship tenable at JKUAT.

\section{REFERENCES}

Akasofu, S and Chapman, S. (1972). Solar Terrestrial Physics, Clarendon press, Oxford, England.

Chanin, M. L. (1988). A review of the 11-year solar cycle, the QBO, and atmosphere relationship, in Middle Atmosphere Program, Handbook for MAP, ICSU, SCOSTEP, J. Lastovichka, Ed., vol. 29, Part 1, pp. 27-30.

El-Metwally, M. (2005). Sunshine and global solar radiation estimation at different sites in Egypt. Journal of Atm. and Solar- Terrestrial Physics, 67:1331-1342.

Falayi, E. O., Rabiu, A. B. (2005). Modelling global solar radiation using sunshine duration data. Nigerian Journal of Physics, 17S:181-186.

Győri, L., Baranyi, T., Turmon, M. and Pap, J. M. (2004). Study of differences between sunspot area data determined from ground -based and space-borne observations, Ad- vances in Space Research, 34:269-273.

Halouani, M., Nguyem, C. T. and Ngoc, D. (1993). Calculation of monthly average global solar radiation on horizontal surface using daily hour of bright sunshine solar energy, 50:247-258.

Iqbal, M. An introduction to solar radiation. Academic press. New York, pp 59-67, 1993.

Labitzke, K. (1987). Sunspots, the QBO, and the stratospheric temperature in the north polar region, Geophys. Res. Lett., 14:535 $-537$.

Labitzke, K., and Chanin, M. L. (1988) Changes in the middle atmosphere in winter related to the 11-year solar cycle. Annales de Geophysique, 6:643-644.

Labitzke, K., and Van Loon, H. (1988). Associations between the 11-year solar cycle, the QBO, and the atmosphere. Part 1: the troposphere and the stratosphere in the northern hemisphere in winter, J. Atmos. Terr. Phys., 50:197-206.

Ndeda, J. O. H., Rabiu, A. B., Ngoo, L. H. M., and Ouma, G. O. (2009). Similarities in Periods of Meteorological variables over Kenya and Solar Activity Periods, Journal of Science and Technology, 29(3):43-51.

Nikolashkin, S. V., Ignatyev, V. M., and Yugov, V. A. (2001). Solar activity and QBO influence on the temperature regime of the subauroral middle atmosphere, $J$. Atmos. and Solar-Terrestrial Physics, 63:853-858.

Scafetta N., and West, B. J., (2003) Solar Flare Intermittency and the Earth's Temperature Anomalies. Phys. Rev. Lett. 90:248701.

Scafetta N., and West, B. J. (2007) Phenomenological reconstructions of the solar sig- 
nature in the $\mathrm{NH}$ surface temperature records since 1600." J. Geophys. Res., 112, D24S03, doi:10.1029/2007JD008437.
Scafetta N., and West, B. J. (2008). Is climate sensitive to solar variability? Physics Today, 3:50-51. 